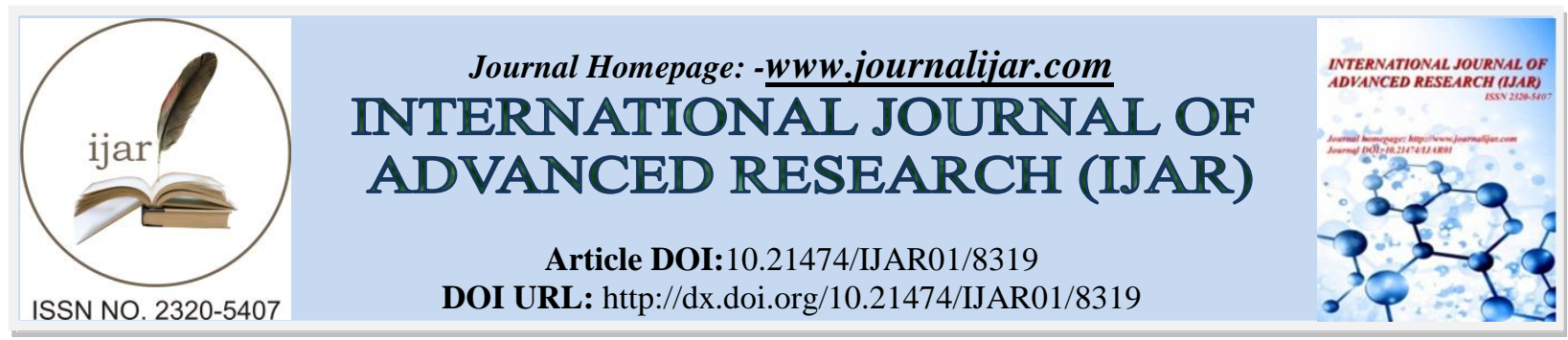

RESEARCH ARTICLE

\title{
CHANGING SCENARIO OF THE PEOPLE GETTING ACCESS TO MENTAL HEALTH CARE CENTRES FOR THEIR MENTAL HEALTH PROBLEMS IN CURRENT TIMES.
}

\author{
Kounsar Sidiq Pandit. \\ Instiute Of Mental Health and Neuro-Sciences, Rainawari Srinagar.
}

\section{Manuscript Info}

\section{Manuscript History}

Received: 04 November 2018

Final Accepted: 06 December 2018

Published: January 2019

Key words:-

Mental health, Stigmas, Intervention,

Clinical Psychologists, Psychiatrist,

Psycho-education.

\section{Abstract}

Mental health is the ability to maintain balance between inner and outer world irrespective of societal or environmental pressures. People suffering from mental illnesses is increasing but the number of patients seeking intervention for their problems with the hope of living better life is also increasing owing to their changing attitudes towards mental health. This paper endeavours to analyze the factors responsible for changing the scenario of people seeking access to mental care professionals with special emphasis on the role of mental health care professionals, family members and mass media.

Copy Right, IJAR, 2018,. All rights reserved.

\section{Introduction:-}

Mental health:-

"Mental health can be defined as one's ability to maintain balance between ones inner and the outer world ,irrespective of the overwhelming pressures of the society /environment".

According to world health organisation "Mental health is state of well being in which every individual realizes his/her own potential, can cope with the normal stresses of life ,can work and productively and fruitfully and is able to make contribution to his/her community"

\section{Changing Attitude \& The Emerging Positive Hope For The Betterment Of Mental Health:-}

Change is an inevitable ongoing process in society since its very beginning. People undergo changes in their whole lives involving various aspects including their attitudes, opinions, behaviour etc. Different people have different motives for accepting or for resisting some particular changes in their lives. The changes which are in accordance with peoples ideas, opinions, values etc takes lesser time to be accepted in the whole society, whereas the changes which are completely contradictory to most peoples, ideas, values, opinions etc takes lot of time and efforts for those involved in heralding and eventually interested in bringing some changes in the society for the betterment of the humanity. The irony is that sometimes people don't even welcome those changes which are for the benefit of human health.

No matter whether people readily accept or resist some changes, the people desperate in making human health/life better keeps on persevering in their respective fields and thereby bring those changes which eventually are for the betterment of the humanity.

Corresponding Author:-Kounsar Sidiq Pandit.

Address:-Instiute Of Mental Health and Neuro-Sciences, Rainawari Srinagar. 
The field of mental health concerned with the mental health of people, involving psychiatrist and psychologists etc is also witnessing some changes. Although these changes are slow as compared to the other fields owing to the various stigmas associated with mental health problems but if we analyze the struggle, this field had undergone since its very beginning, then we can clearly say that the situation is getting better and the efforts are appreciable. This paper endeavours to analyze the factors responsible for changing the scenario of people seeking access to mental care professionals. Efforts would be made to shed light on some points including

1. The increasing urgency for providing the responsible care to patients seeking help for their mental health problems.

2. The role of Mental health care professionals including psychiatrists, clinical psychologists etc.

3. Mental health literacy

4. Education and the role of mass media for creating awareness about mental health problems and their possible interventions.

5. The role of family members

6. The factual information about people having recovered from mental illnesses.

Perseverance of inquisitive minded and responsible people involved in any field of knowledge sheds light on those unknown facts /truth which eventually brings development. The mental health field determined to serve people by helping them in getting proper treatment for their mental health problems/difficulties is also witnessing change, growth and eventual development. This process of bringing desirable changes in the mental health field was initiated long ago by the supporters of the Humanistic approach to the mental health of people. The visionaries involved in this process, noticed that people actually don't consider mental health sign of virtuosity .So if anybody was affected by mental health problem, no care and attention was paid to them. These problems were not considered treatable. The stigmas associated with mental health problems of people, created hurdles for bringing the desirable changes in this field. The indifference and the carelessness towards the psychiatric patients led some eminent research scholars and medical practitioners to instigate changes, which were necessary for preserving the dignity of the humans. The researchers began the process by making people actually realize that healthy mind lives in healthy body, both are equally important. The thing that affects the one, affects the other too. Among the various goals, one of the first and foremost was to get distinct class /category of diseases to mental health problems among various other globally acknowledged health problems.

These efforts started paying off, when after years of struggle, some eminent research scholars and medical practitioners were successful in getting distinct category to mental health problems among the various category of diseases in ICD $6^{\text {th }}$ edition.

If we analyze change and development in terms of increasing number of people seeking intervention for their mental health problems, then we can clearly say that, their is considerable change going on in this field. The number of people seeking interventions for their mental health problems is increasing day by day. The perception of people about mental illness is undergoing huge change becomes evident by the fact that earlier people were even reluctant to discuss their mental health problem and seeking some professional help was far from being consideration of any option.

\section{The increasing urgency for providing the responsible care to patients seeking help for their mental health problems:-}

Statistically it has been found that, in the current modern times, the mental health of the people is much more affected as compared to the earlier times owing to the various pressures that individuals have to deal with for living in the present society. The people affected by the mental health problems dies nearly twenty years early as compared to the other normal people's every fifth person in the society is having mental health condition in their lifetimes, so we can clearly say that huge population is affected by these problems. This situation has created sense of urgency, to make efforts for providing the improved facilities in this field. Because of this attention and propagation of knowledge about the mental health problems of the people and the available intervention , the people have started changing their perspectives about psychiatric illnesses.People have started questioning various social and personal stigmas as it is hindering them from living normal life.

\section{Mental health literacy:-}

Knowledge is power and this power has the potential of bringing bout some desirable changes in the society. Knowledge enlightens people's minds and thereby stimulates them to initiate those changes which help in making 
human life better. Efforts have been and are continuously being made for imparting mental health literacy among the societies. The various community based programmes for providing the mental health literacy to people, from time to time had been very effective in changing the scenario of the people seeking psychological intervention for their problems. From these programmes, common people comes to know that the various psychological /mental problems, their symptoms and their possible treatment options .Efforts are being made to encourage people to talk about their problems and thereby live better life.

Education, Modern technologies and their easy access to educated people:-

Providing education to the people has been the priority of most of the nations. This is because education is a doorway of various developments. When people are educated, their minds tend to be enlightened which helps in stimulating some new perspectives towards the cultural stigmas, about any problem. Nowadays easy access to, modern technologies including internet, mass media etc, helps people to know the mental health problems from different perspective which no longer seems awful. People living in this modern world are prone to lot of stress, anxiety, depression because of various societal pressures. The inquisitiveness of the educated people either personally suffering from or anyone associated with them led them to find the solution of their mental health problems via mass media or internet, even before seeking some professional help. The vast information available because of these technologies creates sense of hope for dealing successfully with the mental health problems and thereby living better life. The detailed knowledge about the various disorders, their successful intervention and results motivates people for availing the help of mental health care professionals.

\section{Role of Family members:-}

It had been found that ,the more aware the family members of the patient are, the more they try to persuade the patient to seek psychological intervention. Whenever, the health of family member gets affected by mental health problem, the whole family suffers as this condition puts extra pressure on all members to deal, support and care for the patient. In such a situation, the family members of the patient makes some real efforts to get the immediate treatment /intervention for the patient. Moreover, no one wants their family members to suffer from any kind of illness.

\section{The factual information about people having recovered from mental illnesses:-}

Those people who (have recovered from psychiatric illness because of timely intervention and treatment) and living in the nearby vicinity of other sufferers (patients of mental health problems) also create powerful impact on the patients and their families to motivate them to undergo treatment. When patients or the patients attendant comes directly in contact with those people who have recovered from mental illness because of treatment, then they start believing in the outcomes of the treatment. The hope of living normal life again develops and motivates the patients to take the first step of approaching the available professionals in the mental health care centers.

\section{The role of mental health care professionals:-}

The humanistic behaviour of the mental health care professionals towards the patients is also responsible for this changing scenario of patients.The appropriate psycho education provided to patients as well as the attendants creates sense of genuiness, empathy etc towards the patient which ultimately help the patient in getting better .The experience of having being treated as humans irrespective of mental health problems creates sense of responsibility among patients and their attendants to guide others to avail the help which would make their life better.

\section{Conclusion:-}

Changing our attitude and our perspective about certain critical issues (mental health) can make and is making difference in leading us towards development and can play significant role in bringing down the alarming rate of the leading cause of disability globally

Bringing flexibility in ones attitude about some detrimental issues of present day life is very crucial if we want to change the society for its betterment .Changing ones perspective is the key to save the world from the leading cause of disability worldwide. People have started realizing that, in order to live happy life, they have to give importance to their own as well as to the mental health of people around them.

Owing to all these factors, we can clearly say that, no doubt the number of people suffering from mental illnesses is increasing but the number of patients seeking intervention for their problems with the hope of living better life is 
also increasing .This is an indication of changing those rigid perspectives of people where the hope for human betterment /humanity lies. Long way to go but the efforts are appreciable,

\section{Refernces:-}

1. Dl vogel,ng wade, a h hckles counselling psychology 2007.

2. Margaritatartakovsky_how to persude your loved ones to seek professionl help. 